\title{
Effect of gallium nitrate on the expression of osteoprotegerin and receptor activator of nuclear factor- $\kappa B$ ligand in osteoblasts in vivo and in vitro
}

\author{
JINGWU LI, GUANG-BIN WANG, XUE FENG, JING ZHANG and QIN FU
}

Department of Orthopedic Surgery, Shengjing Hospital of China Medical University, Shenyang, Liaoning 110004, P.R. China

Received February 13, 2015; Accepted October 26, 2015

DOI: $10.3892 / \mathrm{mmr} .2015 .4588$

\begin{abstract}
Osteoporosis is characterized by the progressive loss of bone mass and the micro-architectural deterioration of bone tissue, leading to bone fragility and an increased risk of fracture. Gallium has demonstrated efficacy in the treatment of several diverse disorders that are characterized by accelerated bone loss. Osteoblasts orchestrate bone degradation by expressing the receptor activator of $\mathrm{NF}-\kappa \mathrm{B}$ ligand (RANKL), however they additionally protect the skeleton by secreting osteoprotegerin (OPG). Therefore, the relative concentration of RANKL and OPG in bone is a key determinant of bone mass and strength. The current study demonstrated that gallium nitrate $(\mathrm{GaN})$ is able to counteract bone loss in an experimental model of established osteoporosis. Ovariectomized (OVX) rats exhibited significantly increased bone mineral density following GaN treatment for 4 and 8 weeks by 19.3 and $37.3 \%$, respectively $(\mathrm{P}<0.05)$. The bone volume of the $\mathrm{OVX}+\mathrm{GaN}$ group was increased by $40.9 \%(\mathrm{P}<0.05)$ compared with the OVX group. In addition, the current study demonstrated that GaN stimulates the synthesis of OPG however has no effect on the expression of RANKL in osteoblasts, as demonstrated by RT-qPCR, western blotting and ELISA, resulting in an increase in the OPG/RANKL ratio and a reduction in osteoclast differentiation in vivo and in vitro.
\end{abstract}

\section{Introduction}

Osteoporosis is characterized by the progressive loss of bone mass and the micro-architectural deterioration of bone tissue, resulting in bone fragility and an increased risk of fracture (1). Gallium is a group IIIA metal and was first identified in 1875 by Paul-Émile Lecoq de Boisbaudran in France (2). Gallium

Correspondence to: Dr Qin Fu, Department of Orthopedic Surgery, Shengjing Hospital of China Medical University, 36 Sanhao Street, Heping, Shenyang, Liaoning 110004, P.R. China

E-mail: li-jingwu@foxmail.com; fuq@sj-hospital.org

Key words: osteoporosis, gallium nitrate, osteoblast, ovariectomized rats, osteoprotegerin, receptor activator of nuclear factor- $\kappa \mathrm{B}$ ligand has been demonstrated to be efficacious in the treatment of a number of diverse disorders that are characterized by accelerated bone loss, including cancer-associated hypercalcemia, bone metastases, Paget's disease, myeloma and fatal cage-layer osteoporosis (2-9). However, the adverse effects associated with gallium limits its use therapeutically for the treatment of osteoporosis (10).

Osteoblasts are key cells involved in bone remodeling. Osteoblasts orchestrate bone remodeling via the expression of receptor activator of nuclear factor $-\kappa \mathrm{B}(\mathrm{NF}-\kappa \mathrm{B})$ ligand (RANKL) in response to osteoclast-stimulating hormones and cytokines, including parathyroid hormone, tumor necrosis factor and interleukin-1, however, in addition they protect the skeleton by secreting osteoprotegerin (OPG) (11). Osteoclasts are important cells in the process of bone resorption, and are predominantly regulated by RANKL and OPG, which are secreted by osteoblasts (12). Therefore, the relative concentrations of RANKL and OPG in bone are key determinants of bone mass and strength. OPG protects bone from excessive resorption by binding to RANKL and preventing it from binding to receptor activator of $N F-\kappa B$ (RANK) (13). Thus, it is suggested that the balance between RANKL and OPG serves an important role in the homeostasis of bone metabolism.

Considering the important role of OPG and RANKL in the regulation of osteoclasts and the inhibitory effects of gallium nitrate $(\mathrm{GaN})$ on ovariectomized (OVX)-induced bone loss (5), the current study hypothesized that GaN may regulate the expression of OPG and RANKL in osteoblasts. Therefore, the aim of the present study was to investigate whether $\mathrm{GaN}$ is able to reduce RANKL and stimulate the expression of OPG in osteoblasts in vivo and in vitro, and thereby inhibit the differentiation of osteoclasts and prevent bone loss in OVX rats. The current study aimed to provide novel insight into the mechanisms of the effect of $\mathrm{GaN}$ on osteoporosis.

\section{Materials and methods}

Chemicals, experimental animals and treatments. GaN was purchased from BetaPharma Co., Ltd. (Shanghai, China).

A total of 45 adult Sprague-Dawley female rats (Experimental Animal Center, Shengjing Hospital of China Medical University, Shenyang, China) at 8-10 weeks of age and 180-200 $\mathrm{g}$ in weight were used. Rats were randomly divided 
into three groups (15 rats/group), all to receive a supplement diet. The rats of two of the groups were to become OVX rats and those in the remaining group underwent a sham operation (control). Within 1 week of their arrival, rats were anesthetized with an intraperitoneal injection of $10 \%$ chloral hydrate (3.0 ml/kg; Tianjin Kermel Chemical Reagent Co., Ltd., Tianjin, China) and underwent either bilateral ovariectomy or a sham operation. Animals were kept separately in stainless-steel cages under controlled laboratory conditions $\left(22-25^{\circ} \mathrm{C}\right.$, $40-60 \%$ relative humidity, $13 \mathrm{~h}$ light/11 h dark cycle) with standard rat chow and water available ad libitum for 2 months. Following this, group $1(\mathrm{n}=15$, sham) and group $2(\mathrm{n}=15, \mathrm{OVX})$ were treated with the vehicle (HyClone ${ }^{\mathrm{TM}}$ phosphate-buffered saline; Thermo Fisher Scientific, Inc., Waltham, MA, USA) by intraperitoneal injection, and group $3(n=15, \mathrm{OVX}+\mathrm{GaN})$ was treated with $\mathrm{GaN}$ injected intraperitoneally $(120 \mu \mathrm{g} / \mathrm{kg} /$ day $)$ for 8 weeks.

All animal experiments were performed in accordance with the international standards for animal experimentation (14). All procedures were reviewed and approved by the Ethical Committee of China Medical University (Shenyang, China).

Measurements of bone mineral density (BMD) using dual-energy X-ray absorptiometry. Dual energy X-ray absorptiometry (XR-600; Norland Medical Systems, Inc., Tustin, CA, USA) was used to scan the left tibia of all rats to determine the level of BMD under chloral hydrate $(3.0 \mathrm{ml} / \mathrm{kg}$ ) anesthesia (for $\sim 20$ min, once per month.

Preparation of tissue. At the time of sacrifice, blood was collected from the dorsal aorta under ether anesthesia (Tianjin Kermel Chemical Reagent Co., Ltd.). Briefly, after the blood was collected, the rats were sacrificed by administering an overdose of the anesthetic. Following centrifugation at $1,800 \mathrm{x} \mathrm{g}$ at $4^{\circ} \mathrm{C}$ for $10 \mathrm{~min}$, serum was harvested and stored at $-20^{\circ} \mathrm{C}$ until analysis. The left tibiae were processed for histology. The right tibiae were processed for immunohistochemistry. The left femurs were processed for reverse transcription-quantitative polymerase chain reaction (RT-qPCR). The right femurs were processed for western blot analysis. All bone tissues were immediately frozen at $-80^{\circ} \mathrm{C}$.

Bone histomorphometry. The tibia tissues were fixed in $4 \%$ formaldehyde (Tianjin Kermel Chemical Reagent Co., Ltd.) for $16 \mathrm{~h}$ at $4^{\circ} \mathrm{C}$ for histological evaluation. Following fixation, tibiae were decalcified in $10 \%$ ethylene diamine tetraacetic acid (Tianjin Kermel Chemical Reagent Co., Ltd.), dehydrated, embedded in paraffin (Beyotime Institute of Biotechnology, Shanghai, China), cut to $5 \mu \mathrm{m}$ sections and stained with hematoxylin and eosin (H\&E; Beyotime Institute of Biotechnology). The tibial analysis was conducted in the proximal metaphysis beginning adjacent to the epiphyseal growth plate. The callus total area, callus bony area and cartilage area were measured using Image-Pro Plus software, version 6.0 (Media Cybernetics, Inc., Rockville, MD, USA).

Immunohistochemistry. For immunohistochemistry, sections were incubated overnight at $4^{\circ} \mathrm{C}$ with a polyclonal goat anti-rat OPG (cat. no. orb11189) and polyclonal goat anti-rat RANKL (cat. no. orb11190; 1:100; Biorbyt Ltd., Cambridge, UK). Goat serum (Solarbio, Beijing, China) was used as the blocking agent. The primary antibodies were detected by incubation $\left(30 \mathrm{~min}\right.$ at $37^{\circ} \mathrm{C}$ ) with an anti-goat $\mathrm{IgG}$ secondary antibody conjugated with horseradish peroxidase (HRP; cat. no. A0227, 1:200; Beyotime Institute of Biotechnology, Haimen, China). Antibody complexes were visualized using a digital microscope (DP73; Olympus, Tokyo, Japan) with 3,3-diaminobenzine solution containing hydrogen peroxide (Beyotime Institute of Biotechnology) and then counterstained using hematoxylin. The integrated optical density was measured using Image-Pro Plus software, version 6.0 (Media Cybernetics, Inc.).

Osteoblast cell culture. Osteoblasts were isolated from the calvariae of four male, 1-day old Sprague-Dawley rats (Experimental Animal Center, Shengjing Hospital of China Medical University) by sequential $0.25 \%$ trypsin and digestion with $0.1 \%$ type II collagenase (HyClone $^{\mathrm{TM}}$; Thermo Fisher Scientific, Inc.). Cells released in the second and third digests were pooled and grown in HyClone ${ }^{\mathrm{TM}}$ Dulbecco's modified Eagle's medium-low glucose medium supplemented with $10 \%$ fetal bovine serum (FBS), $100 \mathrm{IU} / \mathrm{ml}$ penicillin and $100 \mu \mathrm{g} / \mathrm{ml}$ streptomycin (HyClone ${ }^{\mathrm{TM}}$; Thermo Fisher Scientific, Inc.) at $37^{\circ} \mathrm{C}$ in humidified $5 \% \mathrm{CO}_{2}$ air. The cells were regularly trypsinized and subcultured to prevent cell confluence.

Osteoblast cytotoxicity test of GaN. The cytotoxicity of GaN against osteoblasts was investigated using a Cell Counting Kit-8 assay (CCK-8; Beyotime Institute of Biotechnology). In brief, cells were seeded into 96 -well flat-bottomed plates at a density of $5 \times 10^{3}$ cells/well and then placed in serum-starved conditions for a further $6 \mathrm{~h}$. Subsequently, cells were treated with $\mathrm{GaN}$ at increasing concentrations $\left(0,10^{-11}, 10^{-10}, 10^{-9}, 10^{-8}\right.$, $10^{-7}, 10^{-6}$ and $10^{-5} \mathrm{~mol} / \mathrm{l}$ ) in the presence of $10 \%$ FBS for $24 \mathrm{~h}$. Following the $24 \mathrm{~h}$ incubation, $10 \mu \mathrm{l} \mathrm{CCK}-8$ dye was added to each well and incubated for $1 \mathrm{~h}$ according to the manufacturer's instructions. The absorbance of each well was measured at $450 \mathrm{~nm}$ using a microplate reader (Synergy H4; BioTek Instruments, Inc., Winooski, VT, USA).

Enzyme-linked immunosorbent assay (ELISA). Primary osteoblasts were serum starved for $12 \mathrm{~h}$, followed by GaN $\left(10^{-9} \mathrm{~mol} / \mathrm{l}\right)$ stimulation for $24 \mathrm{~h}$. The supernatants of the osteoblasts were then collected. For in vivo and in vitro experiments, the supernatants of the osteoblasts and the serum from the rats were analyzed to measure the concentration of OPG and RANKL using the OPG and RANKL ELISA kits respectively (R\&D Systems Inc., Minneapolis, USA), according to the manufacturer's instructions.

$R N A$ extraction and $R T-q P C R$. The left femurs were placed in liquid nitrogen, bone chips were collected and gently mashed using a mallet. The bone tissues were then ground into a powder in liquid nitrogen using a pestle. For the in vivo and in vitro experiments, the total RNA was extracted from the pulverized bone powder and cells using TRIzol ${ }^{\circledR}$ reagent (Invitrogen; Thermo Fisher Scientific, Inc., Waltham, MA, USA) according to the manufacturer's instructions. The RNA concentration was determined by measuring absorbance at $260 \mathrm{~nm}$, and $1 \mu \mathrm{g}$ total RNA was transcribed to cDNA using the PrimerScript ${ }^{\mathrm{TM}}$ RT 
Reagent kit with gDNA Eraser (Takara Biotechnology Co.,Ltd., Dalian, China) according to the manufacturer's instructions. The primers used were as follows: OPG, forward 5'-GACCCC AGAGCGAAACACG-3' and reverse 5'-GGCACAGCAAAC CTGAAGAA-3'; RANKL, forward 5'-CATCGGGTTCCC ATAAAG-3' and reverse 5'-GAAGCAAATGTTGGCGTA-3'; $\beta$-actin, forward 5'-GGAGATTACTGCCCTGGCTCCTAG C-3' and reverse 5'-GGCCGGACTCATCGTACTCCTGCT T-3'. RT-qPCR was conducted using the Exicycler ${ }^{\mathrm{TM}} 96$ (Bioneer Corporation, Daejeon, Korea) using the following cycling conditions: $95^{\circ} \mathrm{C}$ denaturation step for $10 \mathrm{~min}$ followed by 40 cycles of $95^{\circ} \mathrm{C}$ for $10 \mathrm{sec}, 60^{\circ} \mathrm{C}$ annealing for $20 \mathrm{sec}$ and extension at $72^{\circ} \mathrm{C}$ for $30 \mathrm{sec}$. The detection of the fluorescent product was conducted at the end of the $72^{\circ} \mathrm{C}$ extension period. The housekeeping gene $\beta$-actin was used to normalize the quantities of the target genes. Data were analyzed using the $2^{-\Delta \Delta C q}$ method (15), normalizing levels against those of $\beta$-actin. To evaluate the mean gene expression level, RT-qPCR was performed in triplicate for each sample.

Western blot analysis. The pulverized bone powder was homogenized in radioimmunoprecipitation assay (RIPA) lysis buffer [50 mM Tris pH 7.4, $150 \mathrm{mM} \mathrm{NaCl,} 1 \%$ Triton X-100, $1 \%$ sodium deoxycholate, $0.1 \%$ sodium dodecyl sulfate (SDS); Beyotime Institute of Biotechnology, Shanghai] overnight at $4^{\circ} \mathrm{C}$. Cell pellets were lysed directly in the culture bottles using the RIPA buffer. The lysates were collected and then centrifuged at $16,000 \mathrm{x}$ g for $30 \mathrm{~min}$ at $4^{\circ} \mathrm{C}$. The supernatant was then collected and the total protein levels were measured using a bicinchoninic acid assay kit (Beyotime Institute of Biotechnology).Equalamounts of protein $(40 \mu \mathrm{g})$ were separated by SDS-polyacrylamide gel electrophoresis and transferred onto a polyvinylidene fluoride membrane at $4{ }^{\circ} \mathrm{C}$ (Beyotime Institute of Biotechnology, Shanghai). Following blocking in $5 \%$ fat-free milk for $1 \mathrm{~h}$, the blots were incubated with the following primary antibodies: Anti-OPG (cat. no. orb11189; 1:200, Beyotime Institute of Biotechnology), anti-RANKL (cat. no. orb11190; 1:500, Beyotime Institute of Biotechnology) and anti- $\beta$-actin (cat. no. WL0001, 1:1,000; WanLei Life Sciences, Shenyang, China) at $4^{\circ} \mathrm{C}$ overnight. Membranes were then washed and incubated with HRP-conjugated secondary antibodies (anti-goat IgG; cat. no. A0277; $1: 5,000$ ) at $37^{\circ} \mathrm{C}$ for $2 \mathrm{~h}$. Proteins were detected using enhanced chemiluminescence (Synoptics Ltd., Cambridge, UK). Blots were repeated at least three times for each condition. Following development, the band intensities were quantified using Gel-Pro-Analyzer software, version 4.0 (Media Cybernetics, Inc.)

Statistical analysis. Values are presented as the mean \pm standard deviation and analyzed using the one-way analysis of variance and Student's t-test in IBM SPSS 19.0 software (IBM SPSS, Armonk, MY, USA). All experiments were repeated a minimum of three times, and representative experiments are presented throughout. $\mathrm{P}<0.05$ was considered to indicate a statistically significant difference.

\section{Results}

$B M D$ measurements. The average BMD of rats in each group throughout the experimental period is presented in Fig. 1A.
A

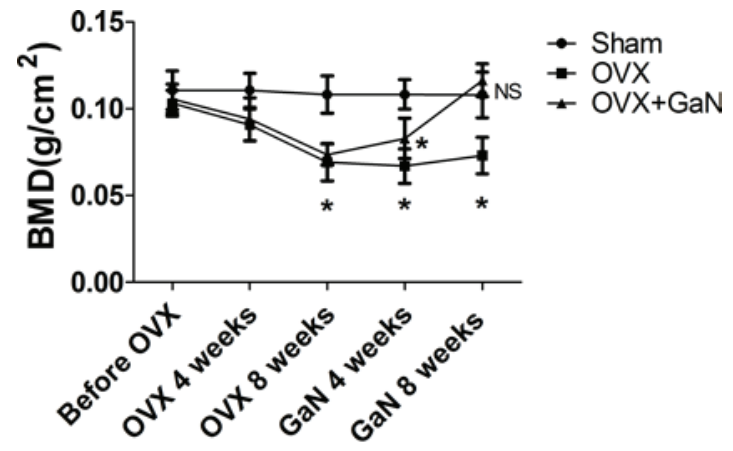

B

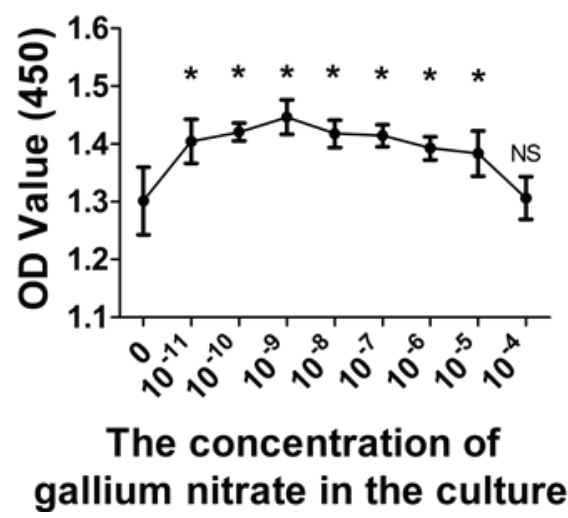

Figure 1. (A) BMD alterations during the experimental period. BMD measurements are from the sham, OVX and OVX + GaN groups, $n=15$ for each group at each time-point. ${ }^{*} \mathrm{P}<0.05$, compared with the Sham group. (B) The $\mathrm{GaN}$ concentration of $10^{-9} \mathrm{~mol} / 1$ resulted in the greatest $\mathrm{OD}$ value. Values are presented as the mean \pm standard deviation. ${ }^{*} \mathrm{P}<0.05$, compared with $0 \mathrm{~mol} / 1$. BMD, bone mineral density; NS, not significant; OVX, ovariectomized rats; GaN, gallium nitrate; OD, optical density.

Following ovariectomy, the BMD of animals was significantly reduced at 4 and 8 weeks $(\mathrm{P}<0.05)$, by 16.5 and $34.1 \%$, respectively. However, the administration of GaN to OVX rats significantly increased BMD at 4 and 8 weeks $(\mathrm{P}<0.05)$, by 19.3 and $37.3 \%$, respectively, compared with the OVX rats.

Bone histomorphometry analysis. To investigate the effect of $\mathrm{GaN}$ on OVX-induced bone loss in vivo, $\mathrm{H} \& \mathrm{E}$ staining (Fig. 2) was conducted. The results of bone histomorphometry analysis were expressed as the percentage of bone volume (BV), mean trabecular thickness (Tb.Th), mean trabecular number (Tb.N) and mean trabecular separation (Tb.Sp). The $\mathrm{BV}$ in the tibia of the OVX $+\mathrm{GaN}$ group increased by $40.9 \%$ $(\mathrm{P}<0.05)$ compared with the OVX group (Fig. 3A). GaN significantly increased the BV in the tibia of OVX rats. The $\mathrm{Tb}$.Th of the GaN treatment group was significantly increased by $43.3 \%(\mathrm{P}<0.01)$ compared with the OVX group (Fig. 3B). The Tb.N exhibited an increase following $\mathrm{GaN}$ treatment of 43.4\% ( $\mathrm{P}<0.05)$ compared with the OVX group (Fig. 3C). In addition, treatment with $\mathrm{GaN}$ led to a reduction in the Tb.Sp by $38.2 \%(\mathrm{P}<0.01)$ compared with the OVX treatment group (Fig. 3D).

Immunohistochemical assessment. To confirm the preventative effect of GaN on OVX-induced bone loss in vivo, 


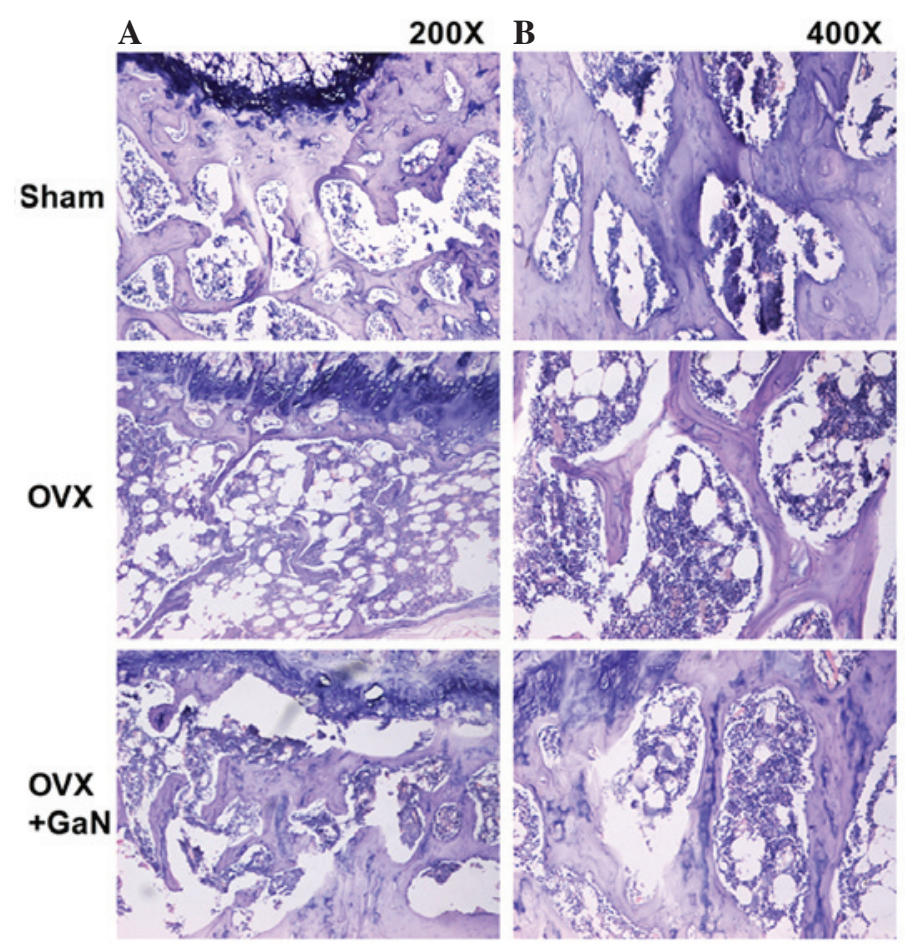

Figure 2. GaN reduces bone loss in OVX rats. Hematoxylin and eosin staining of the metaphyseal region of the proximal tibiae in sham group rats and OVX group rats treated with or without $120 \mu \mathrm{g} / \mathrm{kg} / \mathrm{day} \mathrm{GaN}$ [magnification; (A) x200, (B) x400]. GaN, gallium nitrate; OVX, ovariectomized rats.

A

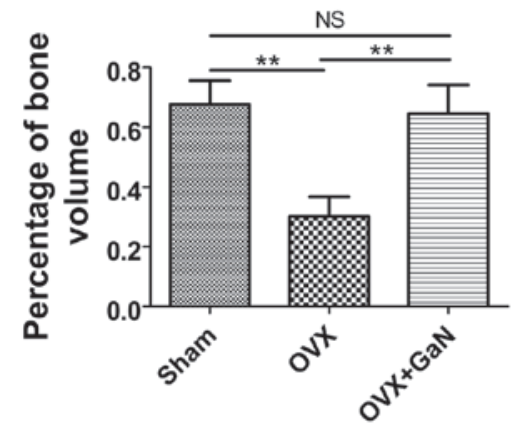

C

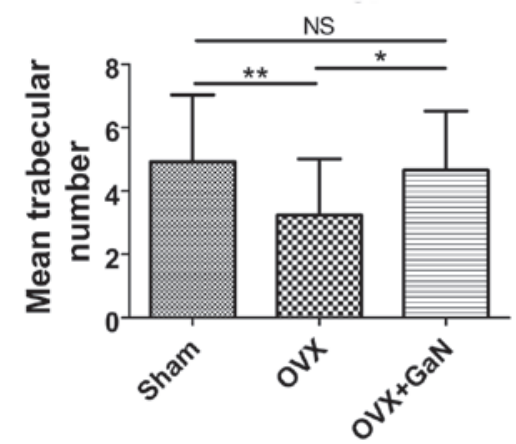

B

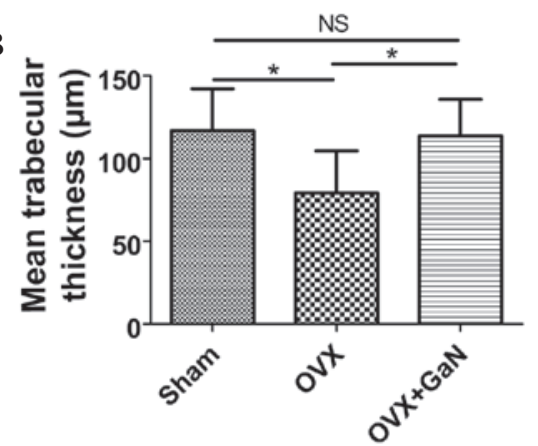

D

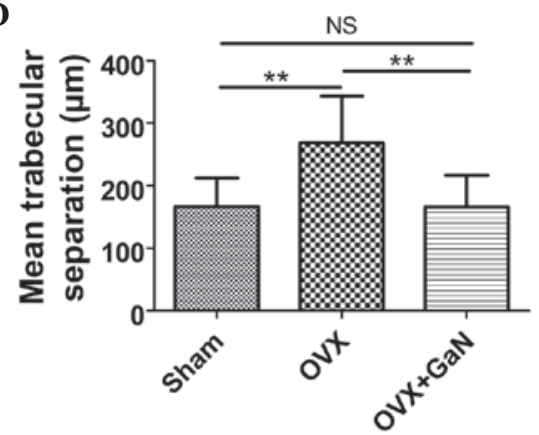

Figure 3. Effects of GaN on bone histomorphometry. (A) The percentage of bone volume. (B) The mean trabecular thickness. (C) The mean trabecular number. (D) The mean trabecular separation. Values are presented as the mean \pm standard deviaiton. ${ }^{*} \mathrm{P}<0.05,{ }^{* *} \mathrm{P}<0.01$. GaN, gallium nitrate; OVX, ovariectomized rats; NS, not significant.

immunohistochemical assessment was conducted to examine the expression of OPG and RANKL in rats. The results demonstrated that $\mathrm{GaN}$ is able to enhance the expression of OPG (P<0.01) compared with the OVX group (Fig. 4), however without affecting the expression levels of RANKL compared with the OVX treatment group (Fig. 5).
Osteoblast cytotoxicity test. The optimal concentration of $\mathrm{GaN}$ was determined using a CCK- 8 assay. For the control, the concentration of GaN was $0 \mathrm{~mol} / \mathrm{l}$. The optical density values of the osteoblasts were greatest following treatment with $10^{-9} \mathrm{~mol} / \mathrm{l}$ $\mathrm{GaN}$. Therefore, this concentration was selected as the optimal concentration of GaN for subsequent investigations (Fig. 1B). 
A

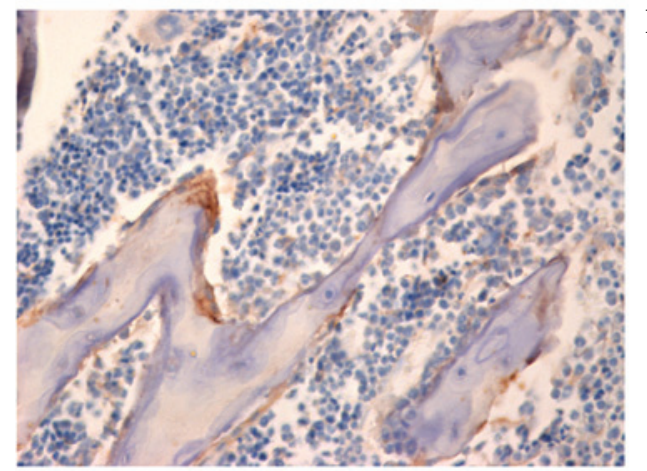

C

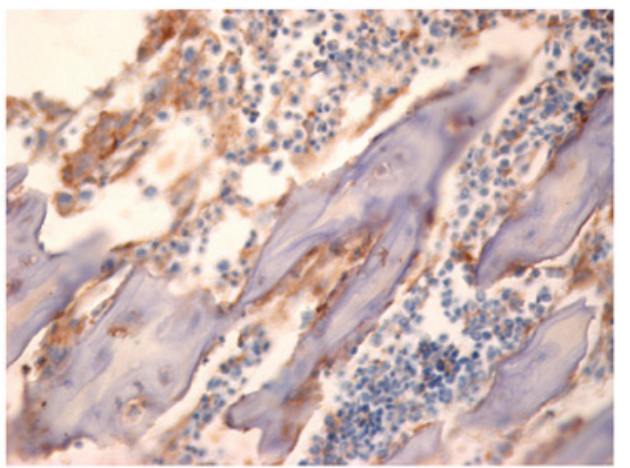

B

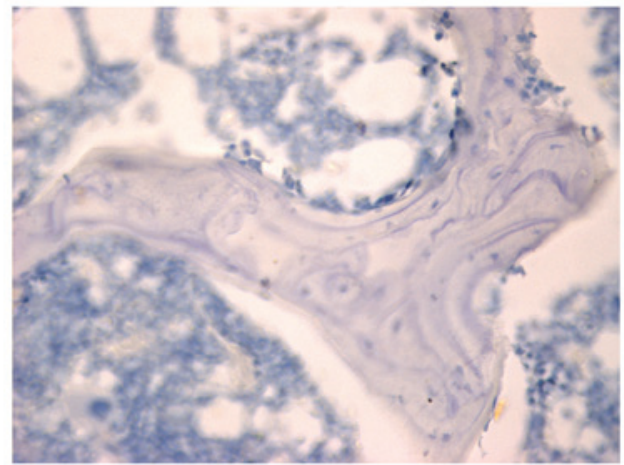

D

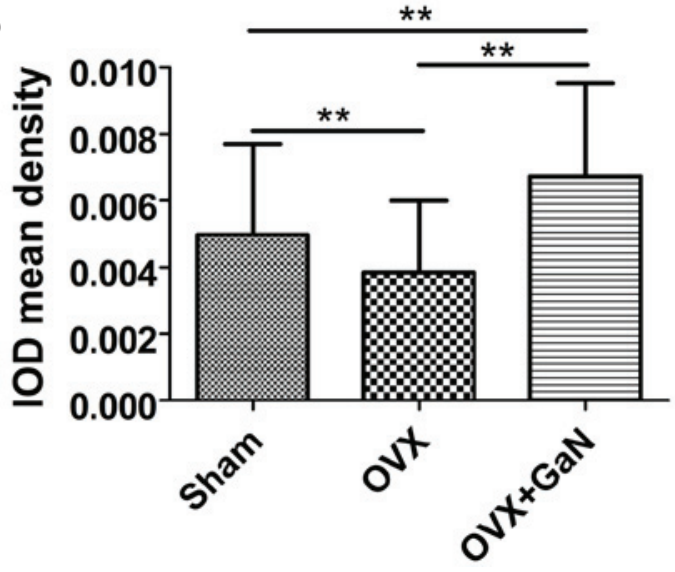

Figure 4. OPG immunohistochemical staining of proximal tibiae sections in OVX rats treated with or without $120 \mu \mathrm{g} / \mathrm{kg} / \mathrm{day}$ of GaN (magnification, $\mathrm{x} 400$ ). (A) Sham group, (B) OVX group, (C) OVX+GaN group and (D) the IOD mean density of OPG expression. Values are presented as the mean \pm standard deviation. ${ }^{*} \mathrm{P}<0.05,{ }^{* *} \mathrm{P}<0.01$. OPG, osteoprotegerin; OVX, ovariectomized rats; GaN, gallium nitrate; IOD, integrated optical density; NS, not significant.

A

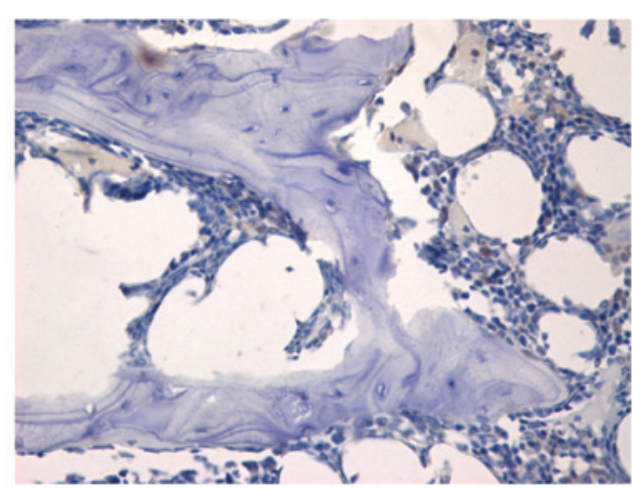

C

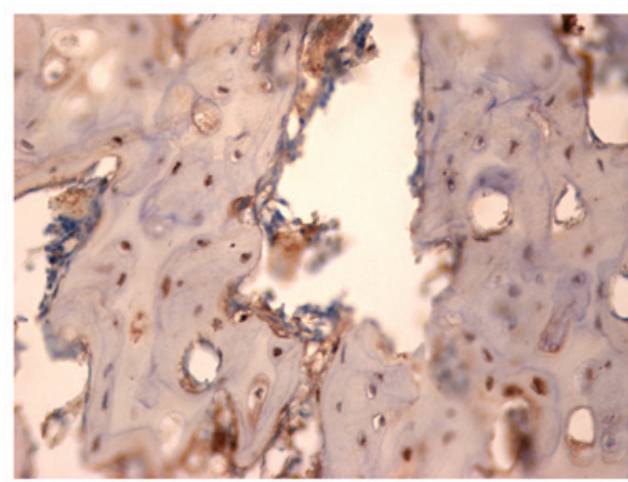

B

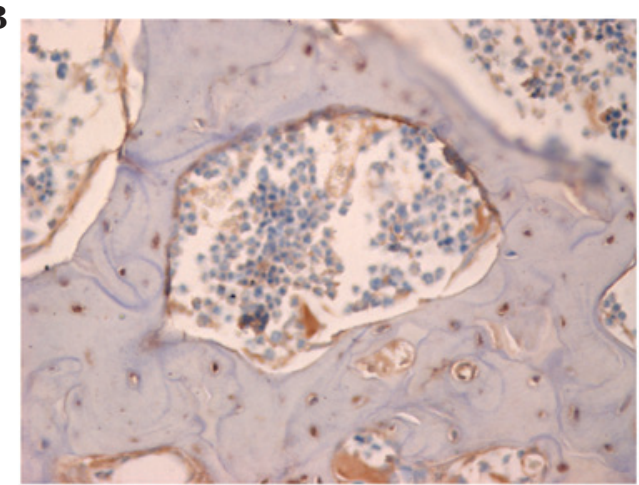

D

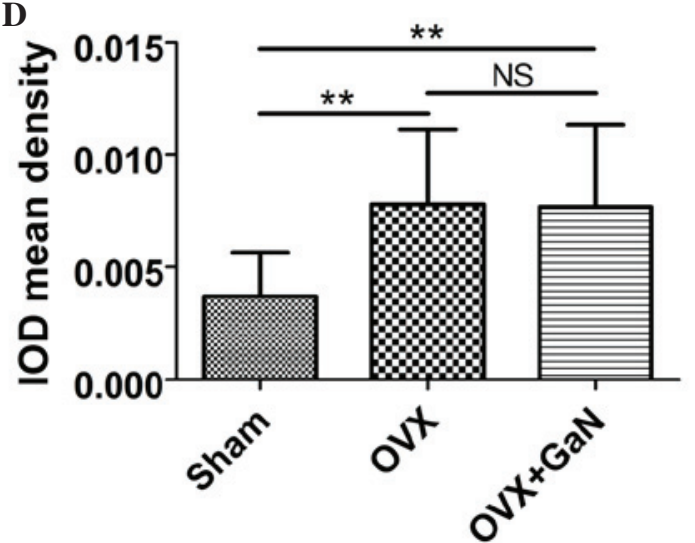

Figure 5. RANKL immunohistochemical staining of proximal tibiae sections in OVX rats treated with or without $120 \mu \mathrm{g} / \mathrm{kg} / \mathrm{day}$ of GaN (magnification, $\mathrm{x} 400$ ). (A) Sham group, (B) OVX group, (C) OVX + GaN group and (D) the IOD mean density of RANKL expression. Values are presented as the mean \pm standard deviation. ${ }^{*} \mathrm{P}<0.05,{ }^{* *} \mathrm{P}<0.01$. RANKL, receptor activator of nuclear factor- $\kappa \mathrm{B}$ ligand; OVX, ovariectomized rats; GaN, gallium nitrate; IOD, integrated optical density; NS, not significant. 
A
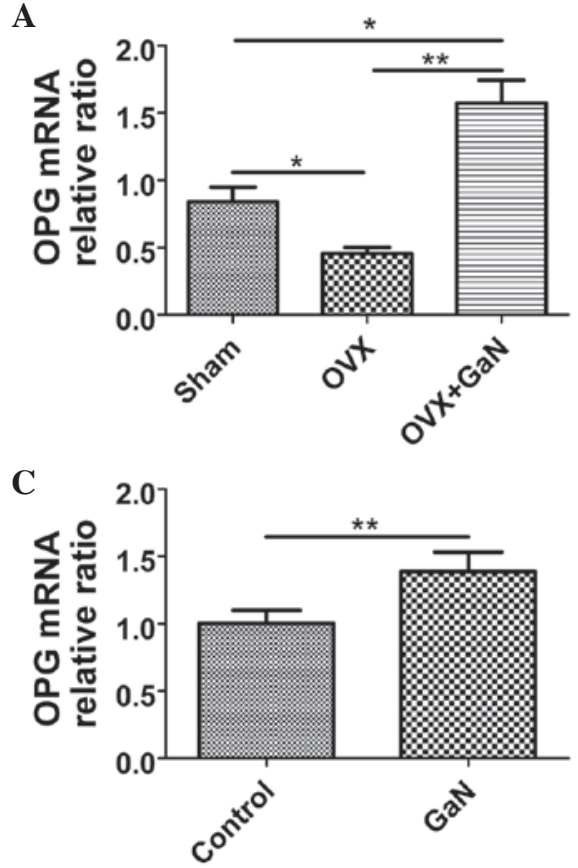

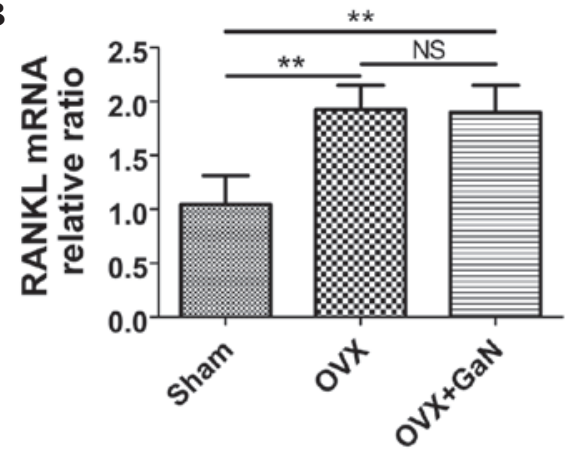

D

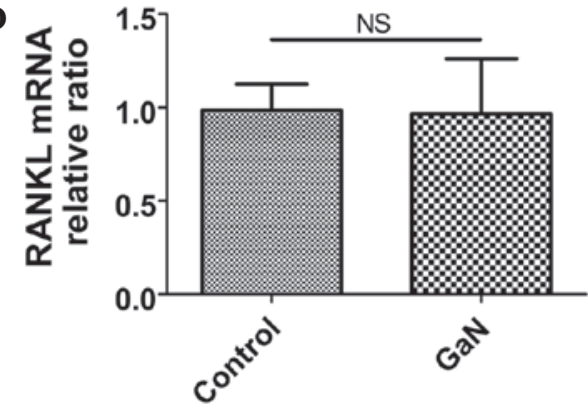

Figure 6. mRNA expression levels of OPG and RANKL in bone tissue were measured by reverse transcription-quantitative polymerase chain reaction. Data were analyzed using the $2^{-\triangle \Delta \mathrm{Cq}}$ method and normalized to $\beta$-actin. (A) The OPG mRNA relative ratio in vivo. (B) The RANKL mRNA relative ratio in vivo. (C) The OPG mRNA relative ratio in vitro. (D) The RANKL mRNA relative ratio in vitro. Values are presented as the mean \pm standard deviation. ${ }^{*}<0.05$, ${ }^{* *} \mathrm{P}<0.01$. OPG, osteoprotegerin; RANKL, receptor activator of nuclear factor- $\kappa \mathrm{B}$ ligand; OVX, ovariectomized rats; GaN, gallium nitrate; NS, not significant.

A

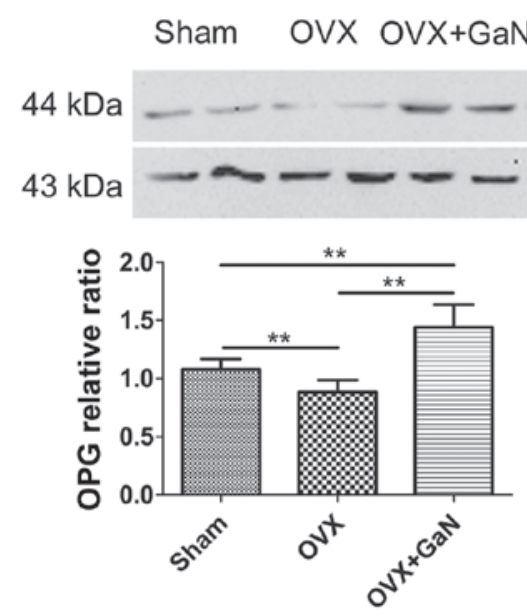

C

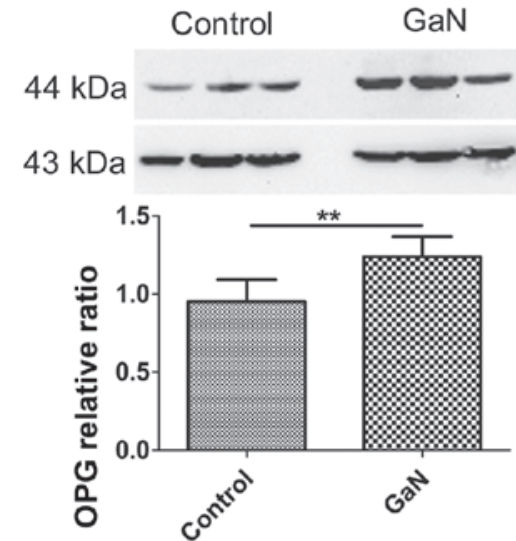

B Sham OVX OVX+GaN
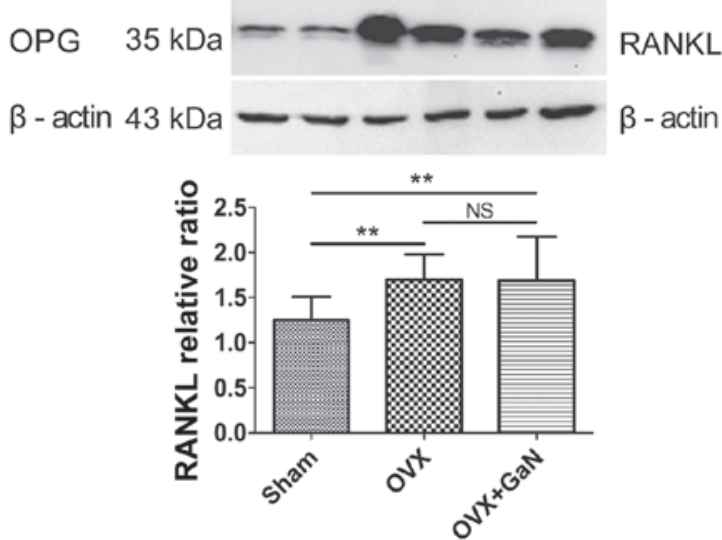

D

Control

GaN
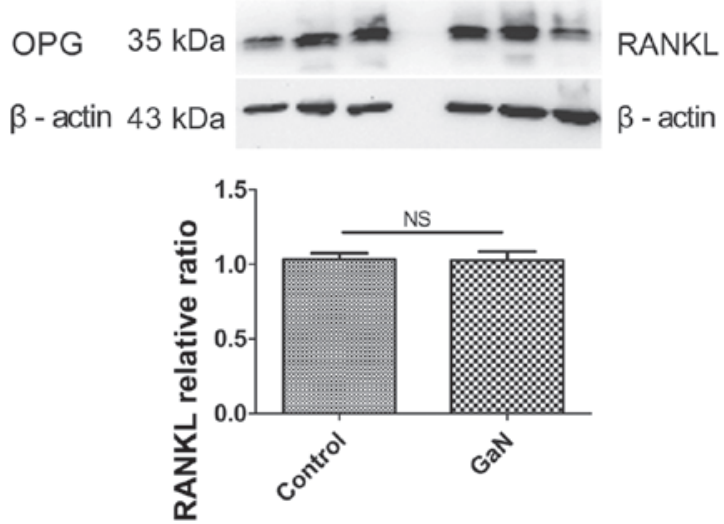

Figure 7. Protein expression levels of OPG and RANKL in bone tissue were measured by western blotting. Data were normalized against $\beta$-actin. (A) The OPG protein relative ratio in vivo. (B) The RANKL protein relative ratio in vivo. (C) The OPG protein relative ratio in vitro. (D) The RANKL protein relative ratio in vitro. Values are presented as the mean \pm standard deviation. ${ }^{*} \mathrm{P}<0.05,{ }^{* *} \mathrm{P}<0.01$. OPG, osteoprotegerin; $\mathrm{RANKL}$, receptor activator of nuclear factor- $\mathrm{B}$ ligand; OVX, ovariectomized rats; GaN, gallium nitrate; NS, not significant. 
A

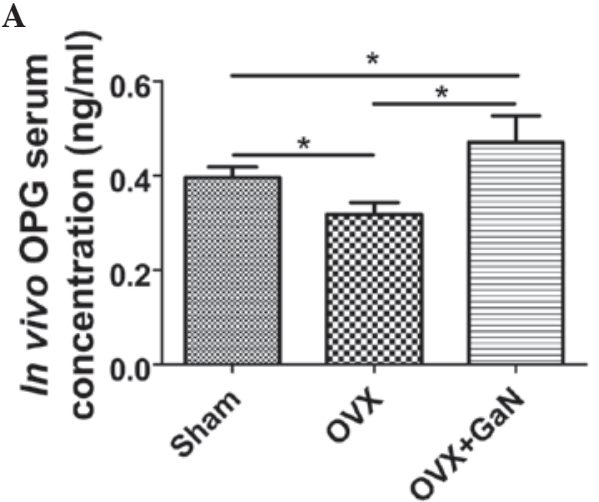

C

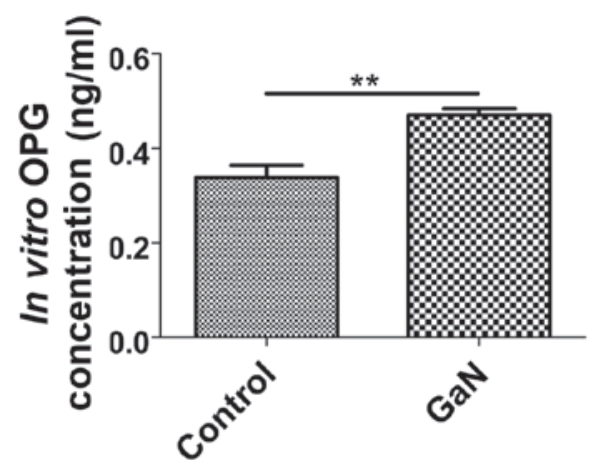

B

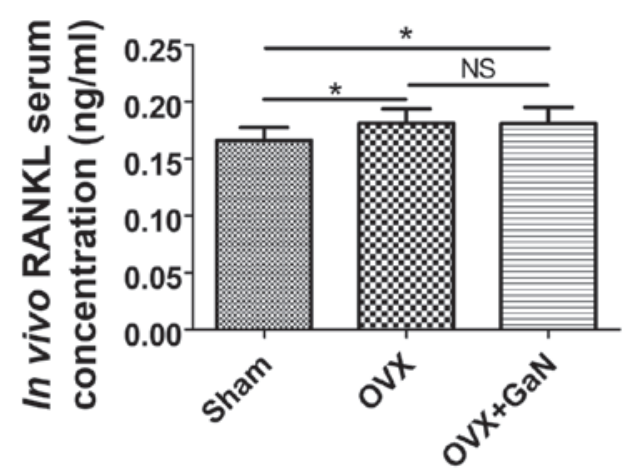

D

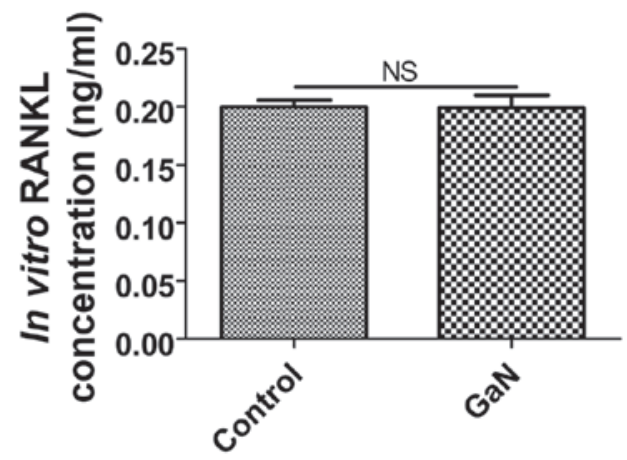

Figure 8. Expression levels of OPG and RANKL in the supernatants of osteoblasts and the serum of rats were measured by the enzyme-linked immunosorbent assay. (A) The serum concentration of OPG in vivo. (B) The serum concentration of RANKL in vivo. (C) The supernatant concentration of OPG in vitro. (D) The supernatant concentration of RANKL in vitro. Values are presented as the mean \pm standard deviation. ${ }^{*} \mathrm{P}<0.05$, $^{* *} \mathrm{P}<0.01$. OPG, osteoprotegerin; RANKL, receptor activator of nuclear factor- $\kappa \mathrm{B}$ ligand; OVX, ovariectomized rats; GaN, gallium nitrate; NS, not significant.

GaN affects the $m R N A$ and protein expression ratio of $O P G / R A N K L$ in vivo and in vitro. To investigate the effect of GaN on OPG and RANKL expression in vivo and in vitro, OVX rats and osteoblasts were treated with GaN, and the mRNA and protein levels of OPG and RANKL in bone tissue were measured using RT-qPCR and western blot analysis, respectively (Figs. 6 and 7). In addition, the expression levels of OPG and RANKL in the supernatants of osteoblasts and the serum of rats were measured using ELISA (Fig. 8). Together, the results indicated that GaN increased the expression levels of OPG, however did not effect RANKL expression in GaN-treated OVX rats and osteoblast cells. These data demonstrate that GaN stimulates OPG however does not affect RANKL expression in vivo and in vitro.

\section{Discussion}

Osteoporosis is the most common bone disorder in aging populations and is an important public health issue, with osteoporotic fractures having a key impact upon health, in terms of acute and long term disability and economic cost (16). The World Health Organization describes osteoporosis as a generalized metabolic disease characterized by progressive loss of the elements of bone tissue and a simultaneous deterioration of skeletal microarchitecture (17), leading to bone fragility and resulting in an increased risk of fractures. Epidemiological data worldwide have consistently demonstrated that the annual incidence of fragility fractures is increasing, in particular in ageing populations (18-23). Furthermore, awareness of osteoporosis is increasing, with this multifactorial disease regarded as a serious public health issue.

Elemental gallium, a group IIIA metal, alters the mineral, matrix and cellular properties of bone $(24,25)$. In animal experiments, gallium has been demonstrated to affect OVX osteopenic rats by reducing serum mineral levels and increasing bone mineral content (26). X-ray diffraction analysis of bone powder from gallium-treated rats demonstrated alterations characteristic of an increase in the size or crystalline perfection of hydroxyapatite minerals (27). The current study demonstrated that GaN treatment resulted in an increase in tibia trabecular bone parameters, BMD and bone strength in OVX rats. The results of histomorphometric analysis indicate that $\mathrm{GaN}$ administration increased the BV and Tb.N, whilst reducing the Tb.Sp in the proximal tibia. These results are in accordance with previous studies which documented the effect of gallium on osteoporosis in OVX rats following short-term treatment $(16,28)$. However, the adverse effects of gallium have limited its use as a therapeutic agent for the treatment of osteoporosis (10). A common adverse effect is hypocalcemia, which on occasion is sufficiently severe to result in transient tetany $(29,30)$. Yeast may be used as an element carrier that is able to convert inorganic elements to organic species and thereby reduce element-associated toxicity (31-33). Previous studies have demonstrated that yeast-incorporated gallium not only reduces gallium-associated toxicity, however additionally 
maintains its therapeutic effect on improving bone loss and promoting fracture healing in OVX female rats $(16,26,28)$.

Bone formation and resorption are normally in physiological balance, maintaining a stable bone mass. At the cellular level, the beneficial effects of gallium are based on a dual effect on osteoblasts and osteoclasts, which control the process of bone remodeling. A previous report by Verron et al (34) indicates that gallium reduces osteoclastic resorption, differentiation and formation in vitro without affecting the viability or activity of primary and MC3T3-E1 osteoblasts. Osteoclasts are key cells in bone resorption, and their differentiation is predominantly regulated by RANKL and OPG. As such, the balance between RANKL and OPG serves a significant role in the homeostasis of bone metabolism (35-39). OPG protects bone from excessive resorption by binding to RANKL and preventing it from binding to RANK. Therefore, the relative concentration of RANKL and OPG in bone is a major determinant of bone mass and strength $(13,40,41)$. The evidence from previous studies led to the current study, which investigated the mechanisms underlying this regulation using an in vivo experimental model of established osteoporosis and an in vitro cell culture system. The present study demonstrated the important role of GaN in the regulation of the OPG/RANKL axis and the inhibition of osteoclastogenesis in vivo and in vitro. These data support the view that $\mathrm{GaN}$ inhibits differentiation of osteoclasts by stimulating OPG without affecting RANKL production in osteoblasts, which may indicate the potential mechanism of GaN in the prevention of post-menopausal osteoporosis.

In conclusion, the current study demonstrates that $\mathrm{GaN}$ is able to counteract bone loss in an experimental model of established osteoporosis. In addition, the data have demonstrated that GaN stimulates the synthesis of OPG without affecting RANKL expression in osteoblasts, resulting in an increase in the OPG/RANKL ratio and a reduction in osteoclast differentiation in vivo and in vitro. These results suggest that GaN may upregulate the secretion of OPG in osteoblasts, and subsequently prevent bone loss and osteoporosis.

\section{Acknowledgements}

The current study was supported by grants from the National Natural Science Foundation of China (grant nos. 81370981 and 81300714).

\section{References}

1. Peck WA: Consensus development conference: Diagnosis, prophylaxis, and treatment of osteoporosis. Am J Med 94: 646-650, 1993.

2. Warrell RP Jr, Bockman RS, Coonley CJ, Isaacs M and Staszewski H: Gallium nitrate inhibits calcium resorption from bone and is effective treatment for cancer-related hypercalcemia. J Clin Invest 73: 1487-1490, 1984.

3. Warrell RP Jr, Skelos A, Alcock NW and Bockman RS: Gallium nitrate for acute treatment of cancer-related hypercalcemia: Clinicopharmacological and dose response analysis. Cancer Res 46: 4208-4212, 1986.

4. Warrell RP Jr, Israel R, Frisone M, Snyder T, Gaynor JJ and Bockman RS: Gallium nitrate for acute treatment of cancer-related hypercalcemia. A randomized, double-blind comparison to calcitonin. Ann Intern Med 108: 669-674, 1988 .

5. Warrell RP Jr: Gallium nitrate for the treatment of bone metastases. Cancer 80 (Suppl): 1680-1685, 1997.
6. Warrell RP Jr, Bosco B, Weinerman S, Levine B, Lane J and Bockman RS: Gallium nitrate for advanced Paget disease of bone: Effectiveness and dose-response analysis. Ann Intern Med 113: 847-851, 1990.

7. Niesvizky R: Gallium nitrate in multiple myeloma: Prolonged survival in a cohort of patients with advanced-stage disease. Semin Oncol 30 (Suppl 5): 20-24, 2003.

8. Li C, Jiang Z and Liu X: Biochemical mechanism of gallium on prevention of fatal cage-layer osteoporosis. Biol Trace Elem Res 134: 195-202, 2010.

9. Chen X and Wang C: Activity of gallium on prevention of fatal cage-layer osteoporosis. Biol Trace Elem Res 132: 129-135, 2009.

10. Foster BJ, Clagett-Carr K, Hoth D and Leyland-Jones B: Gallium nitrate: The second metal with clinical activity. Cancer Treat Rep 70: 1311-1319, 1986.

11. Simonet WS, Lacey DL, Dunstan CR, Kelley M, Chang MS, Lüthy R, Nguyen HQ, Wooden S, Bennett L, Boone T, et al: Osteoprotegerin: A novel secreted protein involved in the regulation of bone density. Cell 89: 309-319, 1997.

12. Teitelbaum SL: Osteoclasts, integrins, and osteoporosis. J Bone Miner Metab 18: 344-349, 2000.

13. Theoleyre S, Wittrant Y, Tat SK, Fortun Y, Redini F and Heymann D: The molecular triad OPG/RANK/RANKL: Involvement in the orchestration of pathophysiological bone remodeling. Cytokine Growth Factor Rev 15: 457-475, 2004.

14. ICLA recommendations for the specification of the animals, the husbandry, and the techniques used in animal experimentation. International Committee on Laboratory Animals - Secretariat. Anat Anz 145: 413-414, 1979.

15. Liss B: Improved quantitative real-time RT-PCR for expression profiling of individual cells. Nucleic Acids Res 30e89, 2002

16. Ma Z and Fu Q: Therapeutic effect of organic gallium on ovariectomized osteopenic rats by decreased serum minerals and increased bone mineral content. Biol Trace Elem Res 133: 342-349, 2010.

17. Goodfellow LR, Earl S, Cooper C and Harvey NC: Maternal diet, behaviour and offspring skeletal health. Int J Environ Res Public Health 7: 1760-1772, 2010.

18. Kanis JA and McCloskey EV: Epidemiology of vertebral osteoporosis. Bone 13 (Suppl 2): S1-S10, 1992.

19. Melton LJ III, Lane AW, Cooper C, Eastell R, O'Fallon WM and Riggs BL: Prevalence and incidence of vertebral deformities. Osteoporos Int 3: 113-119, 1993.

20. van Staa TP, Dennison EM, Leufkens HG and Cooper C: Epidemiology of fractures in England and Wales. Bone 29: 517-522, 2001.

21. Van der Klift M, De Laet CE, McCloskey EV, Hofman A and Pols HA: The incidence of vertebral fractures in men and women: The Rotterdam Study. J Bone Miner Res 17: 1051-1056, 2002.

22. Felsenberg D, Silman AJ, Lunt M, Armbrecht G, Ismail AA, Finn JD, Cockerill WC, Banzer D, Benevolenskaya LI, Bhalla A, et al; European Prospective Osteoporosis Study (EPOS) Group: Incidence of vertebral fracture in europe: Results from the European Prospective Osteoporosis Study (EPOS). J Bone Miner Res 17: 716-724, 2002.

23. Lord SR: Hip fractures: Changing patterns in hospital bed use in NSW between 1979 and 1990. Aust N Z J Surg 63: 352-355, 1993.

24. Repo MA, Bockman RS, Betts F, Boskey AL, Alcock NW and Warrell RP Jr: Effect of gallium on bone mineral properties. Calcif Tissue Int 43: 300-306, 1988.

25. Bockman RS, Boskey AL, Blumenthal NC, Alcock NW and Warrell RP Jr: Gallium increases bone calcium and crystallite perfection of hydroxyapatite. Calcif Tissue Int 39: 376-381, 1986.

26. Bockman RS, Boskey AL, Blumenthal NC, Alcock NW and Warrell RP Jr: Gallium increases bone calcium and crystallite perfection of hydroxyapatite. Calcif Tissue Int 39: 376-381, 1986.

27. $\mathrm{Ma} \mathrm{Z}$ and $\mathrm{Fu} \mathrm{Q}$ : Comparison of the therapeutic effects of yeast-incorporated gallium with those of inorganic gallium on ovariectomized osteopenic rats. Biol Trace Elem Res 134: 280-287, 2010.

28. Pei Y and Fu Q: Yeast-incorporated gallium promotes fracture healing by increasing callus bony area and improving trabecular microstructure on ovariectomized osteopenic rats. Biol Trace Elem Res 141: 207-215, 2011.

29. Bedikian AY, Valdivieso M, Bodey GP, Burgess MA, Benjamin RS, Hall S and Freireich EJ: Phase I clinical studies with gallium nitrate. Cancer Treat Rep 62: 1449-1453, 1978.

30. Krakoff IH, Newman RA and Goldberg RS: Clinical toxicologic and pharmacologic studies of gallium nitrate. Cancer 44: 1722-1727, 1979. 
31. Liu J, Zhang B, He X, Zhang P and Chai Z: Selection of a high-biomass, chromium-rich yeast strain and optimization of cultivation conditions. J Ind Microbiol Biotechnol 27: 195-198, 2001.

32. Han C, Yuan J, Wang Y and Li L: Hypoglycemic activity of fermented mushroom of Coprinus comatus rich in vanadium. J Trace Elem Med Biol 20: 191-196, 2006.

33. Han C, Cui B and Wang Y: Vanadium uptake by biomass of Coprinus comatus and their effect on hyperglycemic mice. Biol Trace Elem Res 124: 35-39, 2008.

34. Verron E, Masson M, Khoshniat S, Duplomb L, Wittrant $Y$ Baud'huin M, Badran Z, Bujoli B, Janvier P, Scimeca JC, et al: Gallium modulates osteoclastic bone resorption in vitro without affecting osteoblasts. Br J Pharmacol 159: 1681-1692, 2010.

35. Yasuda H, Shima N, Nakagawa N, Yamaguchi K, Kinosaki M, Mochizuki S, Tomoyasu A, Yano K, Goto M, Murakami A, et al: Osteoclast differentiation factor is a ligand for osteoprotegerin/osteoclastogenesis-inhibitory factor and is identical to TRANCE/RANKL. Proc Natl Acad Sci USA 95: 3597-3602, 1998

36. Lacey DL, Timms E, Tan HL, Kelley MJ, Dunstan CR, Burgess T, Elliott R, Colombero A, Elliott G, Scully S, et al: Osteoprotegerin ligand is a cytokine that regulates osteoclast differentiation and activation. Cell 93: 165-176, 1998.
37. Anderson DM, Maraskovsky E, Billingsley WL, Dougall WC, Tometsko ME, Roux ER, Teepe MC, DuBose RF, Cosman D and Galibert L: A homologue of the TNF receptor and its ligand enhance T-cell growth and dendritic-cell function. Nature 390: 175-179, 1997.

38. Wong BR, Rho J, Arron J, Robinson E, Orlinick J, Chao M, Kalachikov S, Cayani E, Bartlett FS III, Frankel WN, et al: TRANCE is a novel ligand of the tumor necrosis factor receptor family that activates c-Jun $\mathrm{N}$-terminal kinase in T cells. J Biol Chem 272: 25190-25194, 1997.

39. American Society for Bone and Mineral Research President's Committee on Nomenclature: Proposed standard nomenclature for new tumor necrosis factor family members involved in the regulation of bone resorption. J Bone Miner Res 15: 2293-2296, 2000.

40. Li Y, Toraldo G, Li A, Yang X, Zhang H, Qian WP and Weitzmann MN: B cells and T cells are critical for the preservation of bone homeostasis and attainment of peak bone mass in vivo. Blood 109: 3839-3848, 2007.

41. Hofbauer LC and Schoppet M: Clinical implications of the osteoprotegerin/RANKL/RANK system for bone and vascular diseases. JAMA 292: 490-495, 2004. 